\title{
DISCLAIMER
}

This report was prepared as an account of work sponsored by an agency of the United States Government. Neither the United Slates Government nor any agency thereof, nor any of their employees, makes any warranty, express or implied, or assumes any legal liability or iesponsi. bility for the accuracy, completeness, or usefulness of any information, apparatus, product, or process disclosed, or represents that its use would not infringe privately' owned rights. Reference herein to any specific commercial product. process, or service by trade name, trademark, manufacturer, or otherwise does not necessarily constitute or imply its endorsement, recommendation, or favoring by the United States Government or any agency theteof. The views and opinions of authors expressed hercin do not necessarily state of reffect those of the United States Government or any agency thereof.

PNL-SA--21103

DE92 019137

\section{STATUS REPORT ON THE INTERNATIONAL GERMANIUM EXPERIMENT}

\author{
R. L. Brodzinski \\ J. I. Collar \\ E. Garcia \\ W. K. Hensiey \\ H. S. Miley \\ J. Morales \\ S. B. Osetrov \\ A. A. Pomansky \\ J. H. Reeves \\ C. Saenz \\ M. L. Sarsa \\ A. S. Starostin \\ S. I. Vasiliev
}

F. T. Avignone

H. Courant

C. K. Guerard

I. V. Kirpichnikov

A. Morales

R. Nunez-Lagos

V. S. Pogosor

J. Puimedon

K. Ruddick

A. Salinas

A. A. Smolnikov

A. G. Tamanyan

J. A. Villar

June 1992

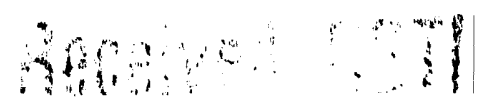

AUG 111992

Presented at the 25 th International Conference on Neutrino Physics June 7-13, 1992 Granada, Spain

Work supported by the U.S. Department of Energy under Contract DE-ACO6-76RLO 1830

Pacific Northwest Laboracory

Richland, Washington 99352

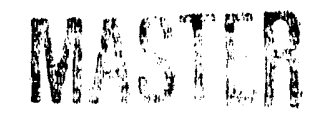


R.L. BRODZINSKI(1), F.T. AVIGNONE(2), J.I. COLLAR(2), H. COURANT(3), E. GARCIA(5), C.K. GUERARD(2), W.K. HENSLEY(1), I.V. KIRPICHNIKOV(4), H.S. MILEY(1), A. MORALES(5), J. MORALES(5), R. NŨNEZ-LAGOS(5), S.B. OSETROV(6), V.S. POGOSOV(7), A.A. POMANSKY'(6), J. PUIMEDÓN(5), J.H. REEVES(1), K. RUDDICK(3), 'C. SÁENZ(5), A. SALINAS(5), M.L. SARSA(5), A.A. SMOLNIKOV(6), A.S. STAROSTIN ${ }^{(4)}$, A.G. TAMANYAN(7), S.I. VASILIEV(6), J.A. VILLAR(5)

(1) Pacific Northwest Laboratory*, Richland, Washington 99352 USA

(2) University of South Carolina, Columbia, South Carolina 29208 USA

(3) University of Minnesota, Minneapolis, Minnesota 55455 USA

(4) Institute for Theoretical and Experimental Physics, 117259 Moscow, Russia

(5) University of Zaragoza, Zaragoza, Spain

(6) Institute for Nuclear Research, Baksan Neutrino Observatory, 361609 Neutrino, Russia

(7) Yerevan Physical Institute, 375036 Yerevan, Armenia

\section{Abstract}

Phase II detector fabrication for the International Germanium Experiment is awaiting resolution of technical details observed during Phase I. Measurements of fiducial volume, configuration of the transistor-reset preamplifier stage, and sources of background are discussed. Cosmogenic $7 \mathrm{Be}$ is measured in germanium. Radium contamination in electroformed copper is reported. The $2 v$ doublebeta decay half-1 1 fe of ${ }^{76} \mathrm{Ge}$ measured with a Phase I detector is in reasonable agreement with previously reported values. No events are observed in the vicinity of the ov double-beta decay energy.

\section{INTRODUCTION}

The goal of the International Germanium Experiment (IGEX) consortium is to provide the most sensitive experiment possible for the measurement of neutrinoless double-beta decay of ${ }^{76} \mathrm{Ge}$. This communication describes recent developments and the current status of efforts by this consortium.

\section{STATUS}

Phase 1 of the IGEX experiment resulted in fabrication of three detectors, each composed of approximately one kilogram of germanium enriched to $87.44 \pm 0.06 \% 76 \mathrm{Ge}$. One of these detectors is currently operating in the Homestake gold mine, one is in the Baksan Neutrino Laboratury, and one is en route to the Canfranc Laboratory. An additional 11 kilograms of enriched ${ }^{76} \mathrm{Ge}$ has been purified, reduced to the metal, and is currently awaiting fabrication into large volume detectors under Phase II of the program.

Several technical details discovered during the operation and testing of the Phase I detectors are currently being resolved before fabrication of the

"Operated for the U.S. Department of Energy by Battelle Memorial Institute under Contract DE-AC06-76RLO 1830. 
Phase II detectors. One of these details concerns an accurate determination of the fiducial volume of the detectors. Early experimental evidence suggests that the dead layer on the p-type crystals is thicker than expected. In order to accurately determine this effective dead layer, and hence determine the active volume, a collimated ${ }^{155} \mathrm{Eu}$ source has been prepared for measuring gamma-ray attenuation as a function of energy, and relating this to thickness of the dead layer. Preliminary experiments indicate this technique will allow a measurement of crystal dead layer thicknesses with an accuracy better than $\pm 0.1 \mathrm{~mm}$.

Another consideration is changing the configuration of the transistorreset preamplifier stage. This design was chosen for Phase I detectors to eliminate the resistor normally used for bleeding off charge buildup since this resistor was presumed to be a source of ${ }^{40} \mathrm{~K}$ in the background. For operational stability considerations, return to the resistor design is preferred for Phase II detectors, and fabrication of special resistors from low-background materials is being investigated. other detalls relative to intrinsic. background are discussed below.

After appropriate testing of Phase II detectors, it is planned that they all be installed and operated in the Canfranc Laboratory. It is also planned to consolidate Phase I detectors in Canfranc.

\section{BACKGROUND REDUCTION}

Following installation of the Phase 1 detector in Homestake, photopeaks from ${ }^{7} \mathrm{Be},{ }^{58} \mathrm{CO}$, and ${ }^{214} \mathrm{Bi}$ were observed in the background spectrum shown in Figure 1. The presence of these radioisotopes was not totally unexpected. The ${ }^{7} \mathrm{Be}$ is a cosmogenic fragmentation product produced primarily in the germanium crystal and was present at an equilibrium co...entration of 1.6 $\mathrm{c} / \mathrm{d} / \mathrm{kg}(0.18 \mathrm{mbq} / \mathrm{kg})$. Fortunately, this 53-day half-life isotope will decay to negligible levels within the course of the experiment. For an interesting comparison, the expected equilibrium concentration based on spallation code calculations' would predict a value of $<0.03 \mathrm{c} / \mathrm{d} / \mathrm{kg}$ for this detector which is significantly lower than actually observed. The explanation is that the code requires the target nucleus to be spalled down to the residual ${ }^{7} \mathrm{Be}$ by emission of individual nucleons, while in reality, many more $7 \mathrm{Be}$ atoms are produced directly as fragmentation products.

The ${ }^{58} \mathrm{Co}$ is also a cosmogenic product, both in the copper cryostat parts and in the germanium crystal, and even though the exposure time to cosmic radiation was minimized as much as possible, there were sufficient reactions to produce a measurable quantity of this 71-day half."life isotope. Again, relatively short half-lives that allow measurable quantities to be produced in briaf periods of time also a low the interference to decay away within ressonable time frames.

Normally, the presence of ${ }^{214} \mathrm{Bi}$ gamma-ray peaks in the spectrum from the IGEX detector would have been assumed to come from radon gas introduced into the lead castie during detector installatiun or during a known subsequent loss of nitrogen gas pressure. However, corresponding peaks were not observed in the "twin" detector also present in the castle from the previous generation experiment. This implies a ${ }^{226} \mathrm{Ra}$ contamination in some component(s) of the IGEX detector that is of different naterial than in the "twin" detector.

Finally, a "peak" consisting of four counts above $5 \mathrm{MeV}$ imply the presence of alpha particle activity incident on the active volume of the 
detector. Since this is a p-type detector, the only active volume accessible by external alpha particles is via the inner coaxial hole. Although this phenomenon was clearly identified in early work ${ }^{2}$, those alpha particles carne from a solder electrical conrection. This phase I IGEX detector has no such connection, and the source of the alpha particles has not yet been identified.

In a previous paper ${ }^{3}$ it was assumed that the ancient "Spanish" lead inner liner contained a small albeit measurable concentration of ${ }^{210} \mathrm{~Pb}$ ostensibly sustained by an original radium or uranium contamination in the 450-year-old lead. In order to verify this assumption, and to test a mechanism for eliminating it, a $2.5-\mathrm{cm}$ thick Marinelli shaped shield was electroformed from copper in the Homestake mine. This process should have eliminated all radioimpurities, including cosmogenic isotopes produced in the copper. This copper "cup" was placed around the "twin" detector because the background spectrum was well known, and since any shielding of ${ }^{210} \mathrm{Bi}$ bremstrahlung radiation by the copper would be obviously manifested in the low-energy portion of the spectrum. Unfortunately, rather than decrease, the background rate increased significantly, and gamma-ray liries from ${ }^{214} \mathrm{Bi}$ and ${ }^{228} \mathrm{AC}$ were abundant in the spectrum. These gamma rays indicate that the electroformed copper cup is contaminated with both ${ }^{226} \mathrm{Ra}$ and ${ }^{228} \mathrm{Ra}$. Apparently, radium present in the elcctroforming bath plates-out along with the copper. The concentrations of ${ }^{226} \mathrm{Ra}$ and ${ }^{228} \mathrm{Ra}$ present in the copper cup are 3.5 and $1.3 \mathrm{mBq} / \mathrm{kg} \mathrm{Cu}$, respectively, and the source of their presence in the electroplating bath has not been identified at this time.

The above radium contamination not only complicates the use of copper as a construction/shielding material, it leaves the question of $210 \mathrm{pb}$ contamination in the Spanish lead unanswered. To verify the presence and concentration of $210 \mathrm{pb}$ in the Spanish lead, another Marinelli cup has been fabricated from ancient Roman lead used as shielding in the Canfranc Laboratory. Unless the Roman lead has the same concentration of $210 \mathrm{~Pb}$ as the Spanish lead, changes in the low-energy region of the spectrum should elucidate the question of ${ }^{210} \mathrm{~Pb}$ contamination in lead samples that are too old to have any remnant primordial $210 \mathrm{pb}$ present.

Because the copper cup was clearly contaminated with radium, the hypothesis was tested that the observed $226 \mathrm{Ra}$ in the IGEX detector was in the copper cryostat parts, particularly since the IGEX detector endcap was electroformed from a different source of copper than used for the neighboring "twin" detector. If the ${ }^{226} \mathrm{Ra}$ is present in the electroformed copper components of the IGEX detector, the concentration is $3.3 \mathrm{mBq} / \mathrm{kg} \mathrm{Cu}$. Although this is the same value as in the copper cup, it is not conclusive proof that the copper is the source of the ${ }^{226} \mathrm{Ra}$. Finally, the concentrations of ${ }^{226} \mathrm{Ra}$ and ${ }^{22.8} \mathrm{Ra}$ reported in $1.92 \mathrm{~kg} \cdot \mathrm{yr}$ of data obtained with the "twin" detectors" were calculated as if they were also present in the copper parts and found to be 0.35 and $0.25 \mathrm{mBq} / \mathrm{kg} \mathrm{Cu}$, respectively. Obviously, if the radium isotopes are present in the electroformed copper, the source of introduction is different for the twin detectors and the IGEX detector.

Another annoying feature of the data acquired with the IGEX detector is the presence of "packets" of pulses. A packet consists of two or more pulses arriving within a fraction of a second. Since the overall count rate of the detector is less than one per hour, the probability that several should arrive within one second is infinitesimal. In fact, "packets" are observed containing ten or more pulses, and these packets can occur several times a day. Although it is easy to identify packets and justifiable to eliminate 
those pulses from the data set, their presence is technically bothersome. The energies of the individual pulses in a packet are typically fairly low, but some have been observed out to several MeV. Of particular concern is the potential for "packets" consisting of only a single pulse to exist, and that pulse to be several MeV. In other words, whatever is causing the false pulses that appear in bunches could be causing single pulses just as easily, and these pulses would otherwise be indistinguishable from "real" background pulses.

Efforts are currently underway to identify and eliminate the source of these packets. Since multiple-pulse packets observed in the "twin" detector data are typically of lower energy and much less frequent, suspicion is cast on the method of mounting the IGEX detector or perhaps the transistor-reset preamplifier, both of which are different than in the "twin" detector. A seismic/acoustic laser interferometer has been assembled and will be installed in the Homestake mine to see if the "packets" can be tagged, and if they can, to see if there are any single-pulse packets being stored.

One final data conundrum involved differences in low-energy pulses $1<150$ keV) stored by a hardwired MCA and the same data stored by a CAMAC based acquisition system. Incoming pulses routed through different amplifiers did not store equivalently in the two systems. The disparity between the spectra increased at lower energies up to as much as a factor of two. Amplifier characteristics and pulse shapes were investigated as sources of these data handling differences, but were not found to create significant differences under normal circumstances. A logic error in the storing of "invalid" pulses was finally determined to be the source of disparity. This problem has now been corrected.

\section{HALF-LIFE MEASUREMENTS}

In order to make room for the IGEX detector in the Homestake configuration, it was necessary to remove the $0.25 \mathrm{~kg}$ enriched ${ }^{76} \mathrm{Ge}$ detector, which was used to make the confirmatory $2 v$ double-beta decay measurements reported previously. ${ }^{5}$ At the time of that publication, the best half-life for the $2 v$ mode was 9.2 . $10^{20}$ yr based on 86.7 days of data accumulation. At the time of retirement, a total of 168 days of data had been acquired with this small enriched detector. This final ${ }^{76} \mathrm{Ge} 2 v$ double-beta decay spectrum, corrected only for the $210 \mathrm{Bi}$ bremsstrahlung, a correction amounting to only $40 \%$ of the total data and most of that below $850 \mathrm{keV}$, is shown in Figure 2 . Undoubtedly some of the events included in this double-beta decay spectrum are attributable to background ganma radiation. However, since no gamma rays were observed in the spectrum, it is difficuit to assess their magnitude. Based on the intensity of gamma-ray peaks observed in the "twin" detectors which operated in the same environment for $1.92 \mathrm{~kg} \cdot \mathrm{yr}$, the best estimate of the contribution to this double-beta decay spectrum from gamma-ray events is $7 \pm 7$ percent. The half-life based on these data with no correction for possible gamma-ray engendered events is

$$
T_{1 / 2}^{2 v}\left({ }^{76} \mathrm{Ge}\right)=\left(8.4_{-0.8}^{+1.0}\right) \cdot 10^{20} \mathrm{yr}(95 \% \mathrm{CL}) \text {. }
$$

Removing the "packets" of pulses from the IGEX spectrum, subtracting only the photopeak areas from the identifiable gamma rays of ${ }^{3} \mathrm{Be},{ }^{58} \mathrm{Co}$, and ${ }_{214} \mathrm{Bi}$, and subtracting a straight line continuum fit to the data between 2150 
and $3050 \mathrm{keV}$ results in corrections amounting to only $18.6 \%$ of the total data. Using the same approach of fitting the residual to the shape of the ${ }^{210} \mathrm{~B} i$ bremsstrahlung spectrum and the ${ }^{76} \mathrm{Ge} 2 v$ double-beta decay specirum results in a half-1ife for the $2 v \beta \beta$-decay of $\left(5.66_{-0.75}^{+0.75}\right) \cdot 10^{20} \mathrm{yr}(95 \% \mathrm{CL})$. This value will increase some small amount after appropriate corrections are made for Compton continua present in the data and may change significantly after an accurate measurement of the dead layer, and hence fiducial volume, is completed, however the shape of the $2 v \beta \beta$-decay component, shown in Figure 3 , is clearly the same as previous measurements. There are no counts in the 30 $\mathrm{keV}$ interval centered on $2038.56 \mathrm{keV}$, the $0 v \beta \beta$-decay energy, as seen in Figure 1, but the elapsed time of data accumulation is too short to draw significant conclusions regarding the neutrinoless double-beta decay mode half-life.

\section{ACKNOWLEDGMENTS}

This work was supported by the National Science Foundation under Grant PHY-9007847, the U. S. Department of Energy under contract DE-AC06-76RLO 1830, and the CICYT (Spain) grant AEN 91-0056. The Canfranc Underground Laboratory is operated by the Institute of Nuclear and High Energy Physics of the University of Zaragoza.

\section{REFERENCES}

1. F.T. Avignone, III, R.L. Brodzinski, J.I. Collar, H.S. Miley, E. Garcia, A. Morales, J. Morales, R. Nuñez-Lagos, J.H. Reeves, C. Saenz, and J.A. Villar, "Theoretical and Experimental Investigation of Cosmogenic Radioisotope Production in Germanium," to be published in Nuclear Physics B.

2. R.L. Brodzinski, J.H. Reeves, F.T. Avignone, and H.S. Miley, Nucl. Instr. and Meth. A254 (1987) 472.

3. F.T. Avignone III, R.L. Brodzinski, J.I. Collar, C.K. Guerard, H.S. Miley, and J.H. Reeves, J. Phys. G: Nucl. Part. Phys. 17 (1991) S181.

4. H.S. Miley, F.T. Avignone, III, R.L. Brodzinski, J.I. Collar, and J.H. Reeves, Phys. Rev. Letts. 65 (1990) 3092.

5. F.T. Avignone III, R.L. Brodzinski, C.K. Guerard, I.V. Kirpichnikov, H.S. Miley, V.S. Pogosov, J.H. Reeves, A.S. Starostin, and A.G. Tamanyan, Phys. Letts. B 255 (1991) 559. 


\section{Figure Captions}

1) Background spectrum acquired in 57 days of counting with the phase I IGEX detector located in the Homestake mine.

2) Two-neutrino double-beta decay spectrum of ${ }^{76} \mathrm{Ge}$ acquired in 168 days of counting with a $0.25 \mathrm{~kg}$ enriched detector in the Homestake mine. The only correction made to this data is for the ${ }^{210} \mathrm{Bi}$ bremsstrahlung originating in the lead shield. The dots represent the actual data, and the smooth curve is the best fit of the anticipated spectral shape.

3) Two-neutrino component of the spectrum shown in Figure 1. 


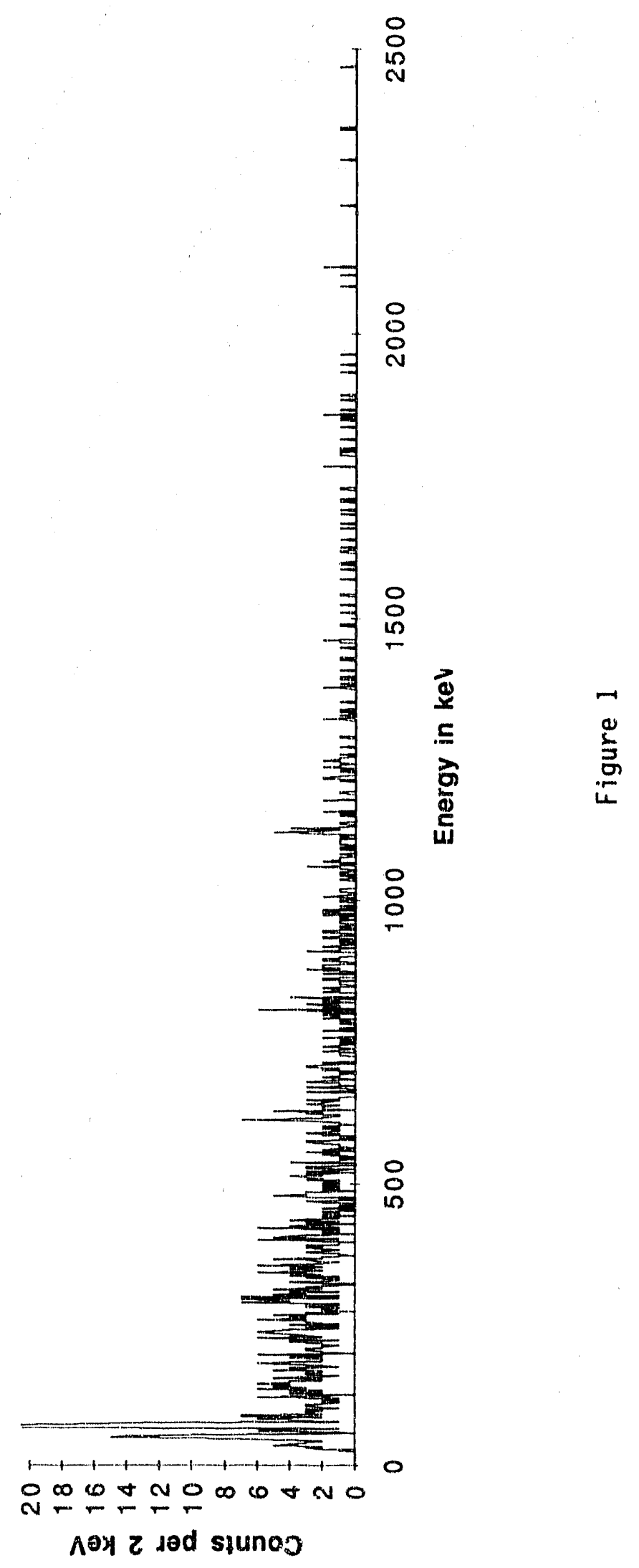




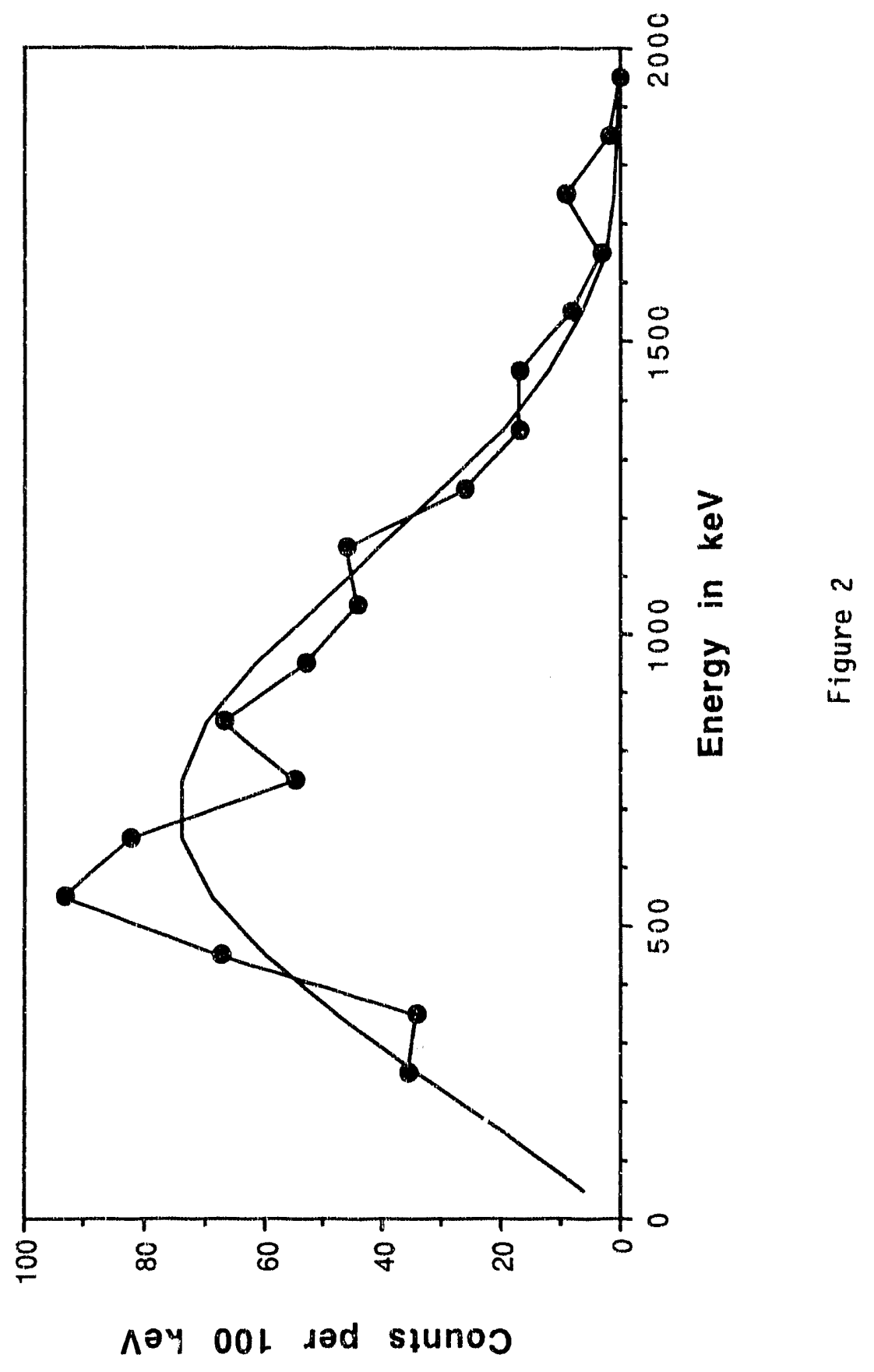




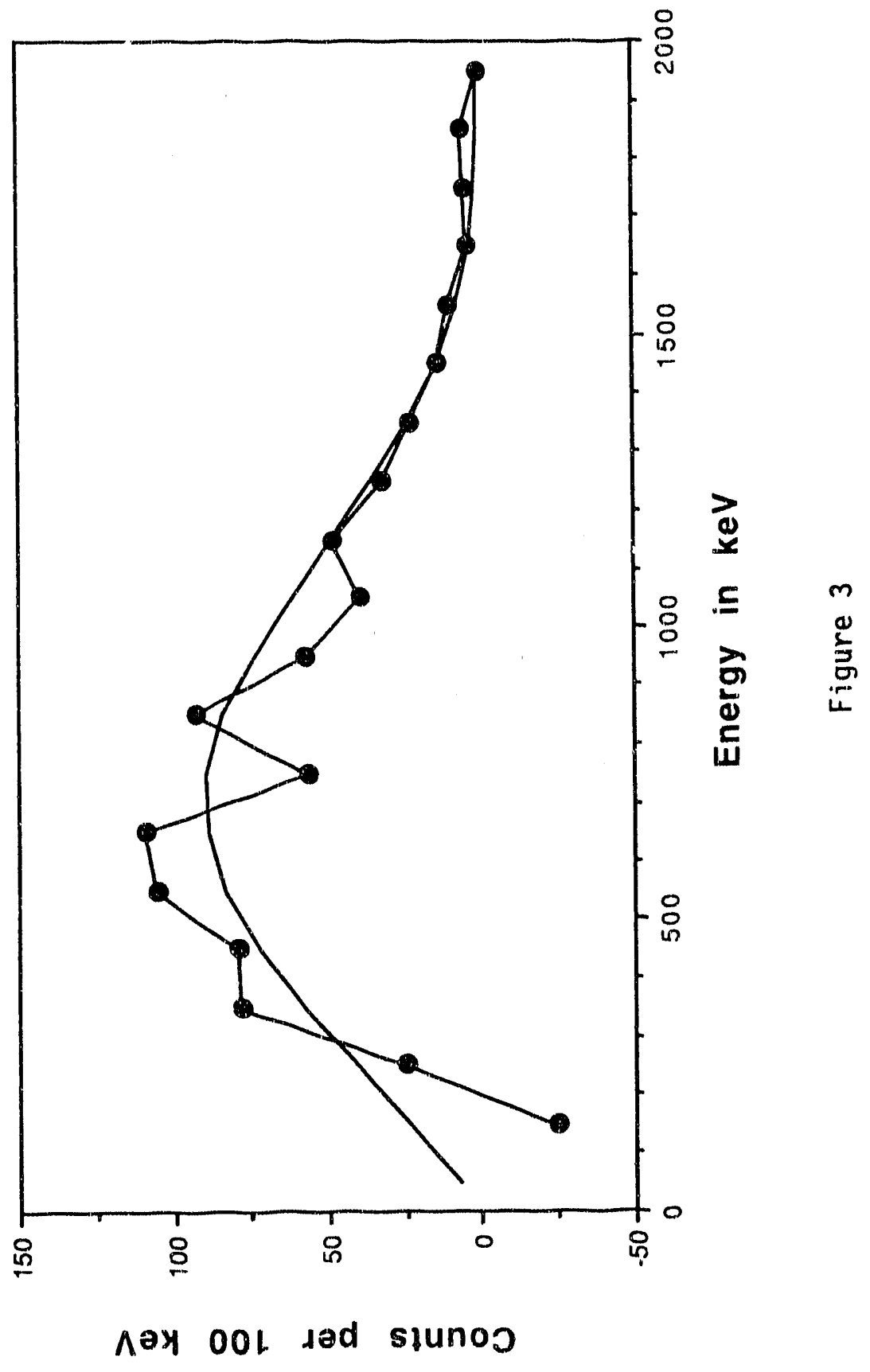



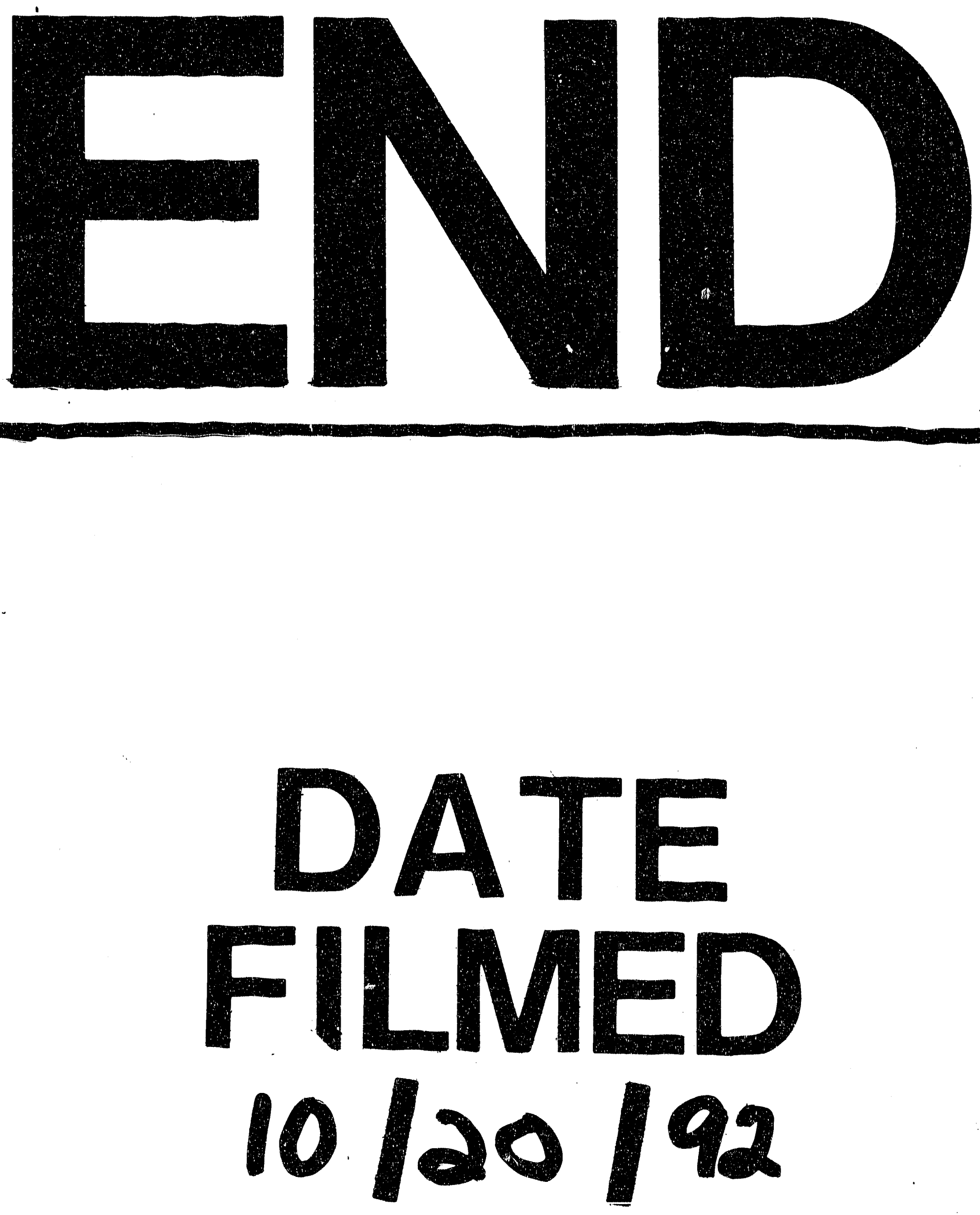


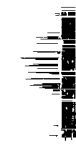

